Hutchinson Katherine, Alessandra (Orcid ID: 0000-0002-3472-8273)

Sallée Jean-Baptiste (Orcid ID: 0000-0002-6109-5176)

de Lavergne Casimir (Orcid ID: 0000-0001-9267-7390)

Luyt Hermann (Orcid ID: 0000-0001-9382-4997)

Fawcett Sarah, E. (Orcid ID: 0000-0002-0878-6496)

\title{
Water Mass Characteristics and Distribution Adjacent to Larsen C Ice Shelf,
} Antarctica

Katherine Hutchinson ${ }^{1,2}$, Julie Deshayes ${ }^{2}$, Jean-Baptiste Sallee ${ }^{2}$, Julian A. Dowdeswell ${ }^{3}$, Casimir de Lavergne ${ }^{2}$, Isabelle Ansorge ${ }^{1}$, Hermann Luyt ${ }^{1}$, Tahlia Henry ${ }^{1,4}$, Sarah E. Fawcett ${ }^{1}$.

1, Oceanography Department, University of Cape Town, Rondebosch 7700, South Africa.

${ }^{2 .}$ LOCEAN Laboratory, Sorbonne Université-CNRS-IRD-MNHN, Paris 75005, France

${ }^{3 .}$ Scott Polar Research Institute, University of Cambridge, Cambridge CB2 1ER, UK

${ }^{4}$ Nelson Mandela University, Port Elizabeth, 6019, South Africa

Corresponding author: Katherine Hutchinson (kath.hutchinson@ gmail.com)

\section{Key Points:}

- Oxygen measurements enable the use of a linear mixing model to quantify contributions from principal source waters.

- High levels of water mass mixing reveal the potential for transformation of the precursors of Weddell Sea Deep Water.

- The observed presence of Modified Warm Deep Water signals the transport of heat to the area.

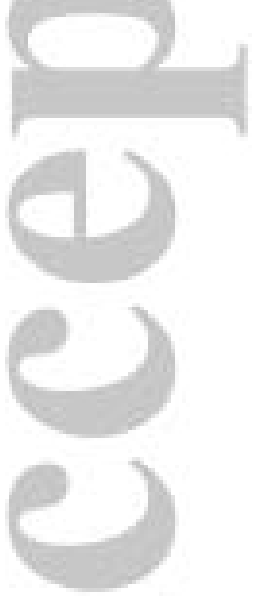

This article has been accepted for publication and undergone full peer review but has not been through the copyediting, typesetting, pagination and proofreading process which may lead to differences between this version and the Version of Record. Please cite this article as doi: 10.1029/2019JC015855 


\section{Abstract}

The physical oceanographic environment, water mass characteristics and distribution in the area adjacent to Larsen C Ice Shelf (LCIS) are investigated using hydrographic data collected during the 2019 Weddell Sea Expedition. The results shed light on the ocean conditions adjacent to a thinning LCIS, on a continental shelf that is a source region for Weddell Sea Deep Water (WSDW), a precursor of the globally important Antarctic Bottom Water. Modified Warm Deep Water (MWDW), a water mass of circumpolar origin, is identified on the continental shelf and is observed to mix with Ice Shelf Water (ISW) and High Salinity Shelf Water (HSSW), both source waters of WSDW. A source water type decomposition analysis reveals high levels of mixing in the area, with much spatial variability. Heat content anomalies indicate an introduction of heat, presumed to be associated with MWDW, into the area via Jason Trough. Furthermore, candidate parent sources for ISW are identified in the region, indicating the potential for a flow of continental shelf waters into the ice shelf cavity; however, the impact on LCIS cannot be surmised from the available observations. ISW and HSSW are observed to make dominant contributions to the densest layers within Jason Trough, where waters are likely en route to feed the deep layers of the Antarctic Slope Current. This cross-shelf flux of water masses links the region of the Weddell Sea adjacent to northern LCIS to global ocean circulation and Bottom Water characteristics via its contribution to ISW and HSSW, and hence WSDW properties.

\section{Plain Language Summary}

A voyage to the Antarctic Weddell Sea in 2019 has enabled a diagnosis of the water mass characteristics adjacent to the northern sector of Larsen C Ice Shelf (LCIS). This region is of interest due to its contribution to the properties of the principal source waters of Antarctic Bottom Water (AABW), a water mass that constitutes the deep limb of the global ocean circulation system. LCIS has recently undergone rapid thinning along with the disintegration of sections of the ice shelf, yet the role of the ocean in these changes remains unclear. It is, therefore, necessary that we improve our understanding of the ocean region adjacent to LCIS. Hydrographic results presented here reveal the presence of a warm water mass in the area, termed Modified Warm Deep Water (MWDW), which has its origins in the Antarctic Circumpolar Current. MWDW appears to thoroughly mix with the local shelf waters such as Ice Shelf Water (ISW) and High Salinity Shelf Water (HSSW), both precursors of AABW. An alteration of water properties on the continental shelf could have important implications for future regional and global ocean circulation, meaning that knowledge regarding the water masses in this area is highly relevant. 


\section{Introduction and Background}

The Weddell Sea is the backdrop for ocean and cryosphere processes that have important implications for local environmental conditions and global climate. Over half of the densest and deepest water in the world's oceans, Antarctic Bottom Water (AABW), is sourced from parent waters formed on the Weddell Sea southern and western continental shelves [Gordon et al., 1993; Orsi et al., 1999; van Caspel et al., 2015; Kerr et al., 2018]. The properties and production rate of this water mass have implications for global ocean circulation and climate regulation as $\mathrm{AABW}$ supplies the lower limb of the global overturning circulation. In recent decades, a freshening ( $\pm 0.004 /$ decade) has been observed in the AABW exported from the Weddell Sea, with the successive disintegrations of the Larsen ice shelves implicated in the alteration of the precursors of AABW [Hellmer et al., 2011; Jullion et al., 2013]. Studies have revealed that Larsen C Ice Shelf (LCIS) has progressively thinned, with Adsumilli et al. [2018] reporting an enhanced thinning of $\sim 1 \mathrm{~m}$ /year from 1999-2008 in the northern region (double the LCIS average). This thinning is thought to be driven by both basal melting via interactions with the ocean, and by enhanced firn melting and compaction due to atmospheric processes [Shepherd et al., 2003; Holland et al., 2015]. A recent finding that the northern section of LCIS is experiencing a faster rate of basal melting than the average for the whole ice sheet [Adsumilli et al., 2018] raises questions regarding the role of the ocean in influencing LCIS and in the reciprocal influence of an input of freshwater on the water mass characteristics on the adjacent continental shelf. As a first step towards improving our understanding of this area, we explore the water mass properties and the extent of mixing on the continental shelf adjacent to the northern sector of LCIS using oceanographic data from the Weddell Sea Expedition 2019 (WSE2019; Figure 1). This dataset is the first to examine the area where Jason Trough joins LCIS at high spatial resolution (Figure 1b).

The water masses located on the continental shelf near LCIS are either locally formed or are transported into the region via the Weddell Gyre's Slope Current (Figure 1a) whereby a combination of wind driven processes, instabilities in the regional gyre circulation, eddies and tides allow for a cross-shelf exchange [Thompson et al., 2018]. Circumpolar Deep Water (CDW) flowing within the Antarctic Circumpolar Current (ACC) enters the Weddell Sea at $\sim 30^{\circ} \mathrm{E}$ and is incorporated into the Slope Current [Gordon et al., 1993; Robertson et al., 2002; Klatt et al., 2005]. This water mass cools and mixes with neighbouring waters along its path within the gyre, becoming Warm Deep Water (WDW) [Robertson et al., 2002]. During winter, Antarctic Surface Water (ASW) loses buoyancy through salinification due to brine rejection during sea-ice formation. On continental shelves, this process can form a hypersaline water mass, termed High Salinity Shelf Water (HSSW), part of which circulates underneath the sub-ice shelf cavities of the Filchner-Ronne Ice Shelf (FRIS) and LCIS (Figure 1a). As the water descends inside the cavities, its freezing point is reduced due to increasing pressure, causing basal melting. As the meltwater rises, partial refreezing to the ice shelf base takes place, with successive melting/refreezing processes ultimately producing Ice Shelf Water (ISW) [Jenkins and Bombosch, 1995; Nicholls et al., 2009]. The Weddell Sea's deep water masses, Weddell Sea Deep Water and Weddell Sea Bottom Water (WSDW and 
WSBW), are fed by a mixture of dense shelf waters (HSSW and ISW) spilling over the continental shelf break and sinking down the continental slope while simultaneously mixing with neighbouring WDW and Modified Warm Deep Water (MWDW) [Fahrbach et al., 1995; Nicholls et al., 2009]. Coriolis deflection acts to direct these water masses north along the western rim of the basin as part of the Weddell Gyre's Slope Current. Once the deep waters escape the Weddell Sea, they are termed AABW [Fahrbach et al., 1995; Gordon, 1998; Orsi et al., 1999]. The main formation site of the source waters of AABW in the Weddell Sea is the vast southern (Filchner-Ronne) continental shelf. However, LCIS is thought to play an important role in setting the properties of WSDW, which is lighter than WSBW and less hindered by bathymetric constraints meaning that it is more easily transported out of the gyre to form AABW [van Caspel et al., 2015; Abrahamsen et al., 2019].

Little is known about water mass mixing and transformation adjacent to LCIS because harsh sea-ice conditions have prevented extensive oceanographic observations. To the best of our knowledge, there have been six major oceanographic expeditions to the region offshore of LCIS: the US-Russian Ice Station Weddell in 1992 [Gordon, 1998], ANT X7 of the Polarstern in 1992/1993 [Bathmann et al., 1994], Ice Station Polarstern in 2004 [Absy et al., 2008], the James Clark Ross (JR71) in 2002 [Nicholls et al., 2004], Polarstern cruise ANT XXIX-3 in 2013 [van Caspel et al., 2015] and the Weddell Sea Expedition in 2019 (WSE2019). Gordon [1998] identified a thick layer of WDW being advected along the western rim of the gyre by the boundary current. The onshore advection of this water mass was observed by Bathmann et al. [1994] who also noted the presence of MWDW in the vicinity of LCIS. This water mass is identifiable as an intermediate-depth temperature maximum that was later reported by Absy et al. [2008] at the mouth of Jason Trough and by Nicholls et al. [2004] at the ice shelf front where the trough abuts the ice shelf (Figure 1b). Nicholls et al. [2004] concluded that by the time MWDW reaches the ice shelf, it has lost the majority of its heat, thereby isolating LCIS from direct contact with WDW of the Weddell Sea. Oceanographic measurements under LCIS obtained from two cores drilled through the ice shelf found the water temperatures in the sub-ice shelf cavity to be at or below sea surface freezing temperature $\left(-1.9^{\circ} \mathrm{C}\right)$, suggesting that MWDW is not melting the base of LCIS [Nicholls et al., 2012]. The sparse and disparate locations of previous observations have limited our understanding of the link between MWDW entering onto the continental shelf [Bathmann et al. 1994] and observations of traces of this warm water mass at a few sites along the ice shelf front [Nicholls et al., 2004]. Questions regarding the transformation of MWDW and the associated heat exchanges taking place adjacent to the ice shelf thus remain highly relevant in terms of the potential modification of the precursors of deep water masses and the potential role of the ocean in driving the thinning of LCIS.

The deep waters of the Weddell Sea are warming and freshening [Purkey and Johnson, 2013; Jullion et al., 2013; Abrahamsen et al., 2019], LCIS has progressively thinned [Shepherd et al., 2004] and basal melting dominates the north-eastern edge of LCIS [Adsumilli et al., 2018]. The western continental shelf of the Weddell Sea is believed to be a region of important ocean-ice shelf interaction, however, the sparseness of observations has not allowed a detailed analysis of these processes in the region. To work towards addressing this, 
we explore the thermohaline properties and extent of mixing between the dominant water masses near LCIS. The data are described in Section 2, the hydrography is examined in Section 3, followed by Sections 4-6 where mixing of water masses in the region is explored. Conclusions are presented in Section 7.

\section{Data}

During the WSE2019, 29 conductivity-temperature-depth (CTD) casts were conducted in the

Weddell Sea in January and February (Figure 1a) with 19 stations located in the region where Jason Trough abuts the ice shelf (Figure 1b). A Sea-Bird SBE 9/11 plus CTD rosette was deployed from the $R / V$ SA Agulhas II to measure temperature, conductivity (which yields salinity) and dissolved oxygen concentrations from the surface to within $10 \mathrm{~m}$ of the sea floor. The CTD rosette housed 24 Niskin bottles that were used to collect salinity and dissolved oxygen samples at various depths that were subsequently used to validate the CTD sensors. Direct salinity measurements verified the accuracy of the conductivity sensor. However, while a strong correlation was observed between the sensor-derived and direct measurements of dissolved oxygen concentrations (Figure S1), the measurements were on average 6.6\% higher; all CTD oxygen data were corrected for this offset (see SI S1).

\section{Hydrography}

To explore the distribution of thermohaline properties observed within the study region, we consider two sections running approximately meridionally and zonally across the sampling area (Figure 2; location of sections shown in Figure 1b). Stable water column conditions are evident along the face of the ice shelf (Figure 2a,b) and along the southern slope of Jason Trough connecting with the ice shelf (Figure $2 \mathrm{~d}, \mathrm{e}$ ). The isopycnals along the ice shelf front dip and shoal considerably between stations (Figure 2a-c). For example, stations 11 and 12 are located in close proximity to one another $(5.5 \mathrm{~km})$, yet have very different thermohaline profiles (Figure 2a,b), highlighting the important role of local processes, such as tides, in shaping density stratification at all depths. The stations located within Jason Trough, on the other hand, show more homogeneous density profiles below 100 dbar (Figure 2d-f).

Subsurface temperature maxima can be seen as yellow-pink bands at depth (Figure 2a,d), indicating the presence of a warmer water mass. These warmer water layers are not characterised by particularly different salinities from the layers above and below, but do coincide with minima in dissolved oxygen (Figure 2c,f). This signature is typical of MWDW, a water mass derived from the mixing of winter water (WW; a subsurface temperature minimum layer) with WDW, a comparatively warm water mass of circumpolar origin. There is, however, no evidence for a coherent, well-preserved MWDW layer, indicating high levels of mixing with ambient waters, in agreement with the findings of Nicholls et al. [2004]. Surface pools of fresher, warmer water with high dissolved oxygen concentrations penetrating to $50 \mathrm{dbar}$ are observed throughout the region and are thought to represent ice melt-water pools (e.g., stations 4, 10 and 12). It is not yet possible to determine whether the source of this freshwater is the ice shelf, icebergs, or sea ice, as the oxygen isotope samples 
collected coincident with the hydrographic data are still being processed and will be the focus of another study.

The temperature versus salinity plots (Figure 3) show that all major Weddell Sea water masses were sampled during WSE2019. The CTD stations located on the continental slope and offshore towards the centre of the gyre (Figure 1a) captured the deep water masses: WDW, WSDW and WSBW (Figure 3a). While the data from these stations are useful and are shown here for context, they will not be discussed in detail. Instead, we focus on the stations located in and around Jason Trough (Figure 1b), for which the subsurface thermohaline properties are shown in Figure $3 \mathrm{~b}$. The only other expedition to undertake hydrographic sampling in this area was that of JR71 in 2002 [Nicholls et al., 2004]. We acknowledge that little can be deduced from comparing the 2002 dataset with the WSE2019 data as these are just two points in time, but we nevertheless include the JR71 measurements [Nicholls et al., 2004] in grey on Figure 3 so as to be comprehensive in showing the available data. The most striking difference between the thermohaline data from the two expeditions is the warmer values for ASW in 2002 compared to 2019 (Figure 3a). Interannual variability in sea ice cover is likely part of the explanation for this, as a relatively broad shore lead was present for JR71 in 2002 (K. Nicholls, pers. comm.), thereby allowing greater heating of the surface layer and reportedly providing a passage for the RSS James Clark Ross to navigate into the region. In contrast, the R/V SA Agulhas II encountered challenging sea ice conditions when maneuvering to the stations shown in Figure 1b. The thick sea ice would have insulated the surface layer from solar heating, possibly explaining the cooler ASW properties measured in 2019 (Figure 3).

The warmest subsurface water mass (temperatures up to $-1.5^{\circ} \mathrm{C}$ ) sampled on the continental shelf is MWDW found in the 200-400 dbar range (Figure 3b), which is fresher and cooler (< $1^{\circ} \mathrm{C}$ ) than WDW due to mixing with WW. The MWDW sampled in 2019 is cooler than that of 2002 (grey dots in Figure 3b), which could be due to a number of factors including variability in surface forcing and mixing processes. The freshest subsurface water mass sampled is WW, while at higher salinities and lower temperatures deeper in the water column, HSSW and ISW dominate (Figure 3b). The HSSW variety presented here is not as salty as that originating from FRIS (maximum measured salinity is 34.63 versus 34.70 at FRIS), but the values coincide with those reported by Nicholls et al. [2004] in the area of interest and by Gordon [1998] on the continental shelf north and south of the sampling area.

It is possible to deduce the salinity of the source water of ISW by making use of a Gade line [Gade, 1979]. This is a line in temperature-salinity space, with a gradient here of $2.4^{\circ} \mathrm{C}$ per salinity unit (PSS-78; such a gradient is appropriate for the western Weddell Sea continental shelf according to Nicholls et al. [2004]). Gade lines are used to determine the salinity of the source water mass at surface freezing point. The two green lines on Figure $3 \mathrm{~b}$ represent \pm one standard deviation of the mean of the observed properties of ISW, with the lower limit of the interval intersecting the surface freezing point at a salinity of 34.60 (Figure $3 \mathrm{~b}$ ). This value represents the minimum salinity of the parent water mass of ISW at the surface, and can thus 
be used to explore whether candidate source waters for ISW are present in our region. All stations at which temperatures were higher than $-1.89^{\circ} \mathrm{C}$ and salinities were greater than 34.60 are located within the core of the trough and where the trough abuts LCIS (Figure 1b, yellow dots). The thermohaline characteristics of waters measured to the north and south of Jason Trough show no evidence for a candidate parent water mass for ISW. We note that the upper limit of the standard deviation of the mean's Gade line for ISW transects the seawater freezing point at a salinity of 34.64. No waters in the region adjacent to LCIS had salinities at or above 34.64, thereby suggesting that this denser variety of ISW was either 1) formed at FRIS and advected northward on the continental shelf, 2) formed at LCIS from a source that entered the cavity from the south, or 3) that a local HSSW source was present but not measured during our sampling of the region. The finding that a portion of the ISW does have candidate source waters on the continental shelf adjacent to LCIS indicates that the sampled HSSW may circulate beneath LCIS and form the lighter variety of ISW observed emerging from the northern LCIS, in agreement with Nicholls et al. [2004].

\section{Linear Mixing Model}

We use an optimum multiparameter (OMP) analysis to estimate the extent of mixing between the four principal water masses observed on the continental shelf adjacent to LCIS [Tomczak, 1981]. The aim is to calculate the relative contributions of "pure" versions of WW, HSSW, MWDW and ISW, referred to as source water types (SWTs; Table S1), to the hydrographic composition of each water parcel within five subsurface density layers: $27.75-27.775 \mathrm{~kg} / \mathrm{m}^{3}$, $27.775-27.80 \mathrm{~kg} / \mathrm{m}^{3}, 27.80-27.825 \mathrm{~kg} / \mathrm{m}^{3}, 27.825-27.85 \mathrm{~kg} / \mathrm{m}^{3}$ and $27.85-27.875 \mathrm{~kg} / \mathrm{m}^{3}$. The method used is effective in extracting the fractional contribution of each water mass to a mixed water parcel, with the important constraint that fractional contributions lie between 0 and 1 in order to satisfy mass conservation [Poole and Tomczak, 1999]. Where the observed water parcel value cannot be explained by a linear mix of the four chosen SWTs (i.e., the measurement lies outside of the mixing matrices shown in Figure 4), no fractional value was assigned, thus explaining the gaps in the pie charts of Figure 5a-e. The fractional contributions of each water mass at each depth are determined by simultaneously solving the following four equations:

(1) $F w w+F h s s w+F m w d w+F i s w=1$

(2) $(F w w \times T w w)+(F h s s w \times T h s s w)+(F m w d w \times T m w d w)+(F i s w \times T i s w)=$ Tobs

(3) $(F w w \times S w w)+(F h s s w \times S h s s w)+(F m w d w \times S m w d w)+(F i s w \times S i s w)=S o b s$

(4) $(F w w \times O w w)+(F h s s w \times O h s s w)+(F m w d w \times O m w d w)+(F i s w \times O i s w)=$ Oobs

Where $F w w, F h s s w, F m w d w$ and Fisw represent the fractional contributions of the source water types WW, HSSW, MWDW and ISW to the measured water parcel. The properties of the source water end members are represented by $T, S, O$. To explore the sensitivity of the fractional contributions to the choice of the SWT value, the OMP analysis was performed 40 times (deemed appropriate to stabilize the magnitude of standard deviations) with slightly different SWT values (see SI S3), and the mean and standard deviations of each fractional result were compared with those from Figure 5 (Figure S3). For each OMP run, the value of 
the SWT was randomly selected for each water mass from a range of values surrounding the SWTs defined in Table S1 (Figure S2). This sensitivity test shows that moving SWT values within a reasonable range does not have a major effect on the resultant fractional contributions. The SWT values chosen for the OMP analysis presented in Figure 5 were selected so as to incorporate the majority of observations below $100 \mathrm{~m}$ within a linear mixing matrix between the four water masses (Figure 4), while simultaneously keeping the SWT values in line with known water mass properties (Table S1). Tobs, Sobs and Oobs represent the measured temperature, salinity and dissolved oxygen values at each depth.

The presence of iceberg A-68 in the region is not thought to have strongly affected the water mass characteristics on the continental shelf at the depths that we consider in our OMP analyses for the following reasons: 1) The iceberg draft would be equal to or less than that of LCIS (180 m; Timmermann et al. [2010]), and we are principally interested in water masses located deeper than this, 2) the iceberg had very recently moved into the area, and we expect a longer residence time for modification of the water masses of interest, and 3) it is unlikely that the requisite sub-ice shelf processes responsible for ISW production (discussed in Section 1) would be mimicked offshore under an iceberg.

\section{Heat Content Analysis}

The heat content (HC) for the depth interval 150-350 dbar was computed according to the following equation:

(5) $H C=\int_{350 d b a r}^{150 d b a r} \rho C_{p} T d z$

where $\rho$ is the in-situ density, $C_{p}$ is the heat capacity of seawater at constant pressure (4000 $\mathrm{J} . \mathrm{kg}^{-1} \cdot \mathrm{K}^{-1}$ ) and $T$ is the measured temperature. The interval $150 \mathrm{dbar}$ to $350 \mathrm{dbar}$ was chosen as this spans the approximate total depth range of the density layers for which the OMP analysis was computed (Figure 2; Figure 5a-e). Note that the HC was not computed for density layers as the changing thickness of the interval between isopycnals obscures the comparison between CTD stations. It is thus essential that the HC presented is for the same depth range everywhere and so for stations where the maximum sampled depth is shallower than $350 \mathrm{dbar}$, no HC value was assigned. The mean $\mathrm{HC}$ for the 150-350 dbar depth layer for the region shown in Figure $1 \mathrm{~b}$ was computed and the anomalies from the mean are presented in Figure 5f. Positive $\mathrm{HC}$ anomalies dominate the south-western portion of the study region, with the largest warm anomaly situated in close proximity to LCIS (station 16, Figure 5f). The pattern of $\mathrm{HC}$ anomalies will be discussed further in the next section in the context of the water masses present.

\section{Water Mass Mixing}

To better understand the various contributions of water masses in the area to the ocean properties adjacent to LCIS, Figure 5a-e shows the relative percentage contributions of each 
of the four principal water masses found in the area (WW, ISW, HSSW and MWDW) to the measured characteristics in five density layers. Together, these density layers cover the approximate depth range of 150-350 dbar, in line with the depth interval used to compute the $\mathrm{HC}$ anomalies. We note that due to the limited bathymetric measurements in the area, despite being the best product available, the background shading of IBSCO bathymetry (Figure 5; Arndt et al., [2013]) is an interpolated grid and may be subject to high error. Therefore, at some locations there is a disagreement between the maximum depth of the CTD cast and the IBSCO bathymetry (e.g. station 9 maximum depth was actually 318 dbar versus the reported sea floor depth from IBSCO of $380 \mathrm{dbar}$ ).

The upper subsurface layer $\left(27.75-27.775 \mathrm{~kg} / \mathrm{m}^{3}\right.$; Figure 5a) is dominated by WW with small contributions from other water masses. This is to be expected at this relatively shallow depth, especially as the properties defined for the source water type "WW" (SI Table S1) are effectively a combination between ASW and WW as the upper bound of the temperature range of WW was used so as to include more data in the linear mixing matrix (Figure 4). The dominance of WW is maintained for the underlying density layer $\left(27.775-27.80 \mathrm{~kg} / \mathrm{m}^{3}\right.$;

Figure 5b); however, here there is a sizeable increase in the fractional contribution from ISW, with small contributions from HSSW and MWDW. The largest percentages of HSSW in this layer are located at the apex of Jason Trough (e.g., stations 10-13). The MWDW contribution is greatest on the southern slope of the trough (e.g., stations 14 and 16) and the proportions of this water mass are generally larger in the south of the domain. Relative to the overlying layer, the intermediate layer $\left(27.80-27.825 \mathrm{~kg} / \mathrm{m}^{3}\right.$; Figure $\left.5 \mathrm{c}\right)$ is characterised by larger percentages of MWDW and ISW and smaller contributions of WW. The stations with the largest proportion of MWDW (7, 12, 14 and 16) are located on the southernmost edge of the slight ridge connecting Jason Trough to the sub-ice shelf cavity of LCIS. These stations also possess the largest HC anomalies (Figure 5f). Figure S2 (SI) shows an example of the typical signature of MWDW such as that sampled at station 7, contrasted with profiles from stations 5 and 11 which, despite being immediate neighbours to the east and west, display no evidence of a large contribution from MWDW.

Similar to the intermediate layer, the deep density layer $\left(27.825-27.85 \mathrm{~kg} / \mathrm{m}^{3}\right.$; Figure $\left.5 \mathrm{~d}\right)$ comprises large fractions of MWDW mixed with much colder ISW. The larger fractions of MWDW observed in the centre of the trough and along the southern slope are consistent with the pattern of circulation hypothesised by Nicholls et al. [2004], whereby MWDW is proposed to advect towards LCIS from the east along the axis of Jason Trough that connects the sampling area with the shelf break and Slope Current (Figure 1). While not all stations are well represented in the bottom density layer $\left(27.85-27.875 \mathrm{~kg} / \mathrm{m}^{3}\right.$; Figure 5e), either because they are too shallow or because the data are out of the range of the linear mixing matrix of the OMP analysis, the available results show strong mixing between MWDW, HSSW and ISW at the base of the water column.

Findings from the OMP analysis (Figure 5) reveal fingerprints of mixing between MWDW, a water mass of circumpolar origin, and local continental shelf waters. This mixing removes/redistributes heat from MWDW, likely acting to protect the ice shelf from 
interacting with a relatively warm water mass, which would otherwise induce enhanced basal melting [Nicholls et al., 2004]. ISW formed in the ice shelf cavity below LCIS at the western edge of the study region is expected to flow out of the cavity and over the ridge in the vicinity of stations 10-13 (Figure 5d). A dense shelf water mixture of HSSW and ISW is then expected to migrate out of the area of interest following the depression of Jason Trough (Figure 5d,e). When ISW and HSSW flow down the continental slope and are modified via mixing with neighbouring water masses [Fer et al., 2016], they become WSDW (or WSBW, if deriving from a denser source water variety). Only once this deep water is exported out of the Weddell Sea is it known as AABW. The production and properties of this water mass are critical for ocean heat and carbon storage as AABW fills the bulk of the deep ocean [Johnson 2008].

The colocated large contributions of MWDW, ISW and HSSW to the properties of the waters sampled in the centre of the trough (e.g., stations 4-6 and 18; Figure 5d,e) raise the possibility of entrainment of MWDW into the source waters for WSDW as they flow towards the shelf break within Jason Trough. This finding has important implications for the possible influence that an alteration of the properties of MWDW might have on WSDW, and thus AABW, through mixing akin to that observed. Possible causes for a change in MWDW properties are an increase in cross-shelf transport of WDW/MWDW due to variations in the Antarctic Slope front or thermocline depth and/or a warming of CDW.

\section{Conclusions}

The observations obtained during WSE2019 shed light on the summertime properties of water masses adjacent to the northern sector of LCIS. Challenging environmental conditions have thwarted previous attempts to obtain observations in this area. The data presented here thus help to elucidate the oceanographic conditions in an extremely data-sparse region. CTD sampling efforts were focused within the topographic depression of Jason Trough, specifically where the trough connects with LCIS, and provide the highest spatial resolution dataset to-date for this area. The presence of the newly calved A-68 iceberg is assumed to not significantly affect water mass properties in the depth range of our analysis; however, further work on the role of icebergs in continental shelf circulation and properties is crucially needed but beyond the scope of this study.

OMP analysis reveals a high degree of interaction between WW, ISW, HSSW and MWDW in the subsurface layers on the continental shelf near LCIS. The pattern of water mass fractional contribution to observed temperature, salinity and oxygen concentration properties together with the heat content anomalies support the circulation pattern proposed by Nicholls et al. [2004] for the area: namely, that MWDW could be transported onshore in the south of the domain as a topographically driven flow following the Jason Trough. We find that the heat that MWDW brings into the area is redistributed via effective mixing with local shelf waters (WW, HSSW and ISW), but we cannot identify the potential impact of this introduction of heat on the ice shelf with the available data. Candidate source waters for ISW are identified in the sampling region, revealing the possibility for the circulation of local 
HSSW underneath LCIS. In order to clarify whether MWDW has an impact on basal melting of LCIS, further analysis is needed (e.g., using oxygen isotope measurements of seawater, for example) along with direct measurements of the local shelf circulation (e.g., using moorings). ISW and HSSW sampled within Jason Trough, surmised to be following the main axis of the trough out to the open Weddell Sea, are found to mix with MWDW. Continued observations in the area and on the continental slope, together with an adept ocean model, are needed to clarify the impact of this mixing on the properties of WSDW and the repercussions for AABW characteristics.

\section{Acknowledgments and Data}

The authors would like to thank two anonymous reviewers for comments and suggestions that improved this manuscript. We would also like to thank the Flotilla Foundation and the Weddell Sea Expedition 2019 for financial support and for providing the opportunity to collect the data presented in this paper. We would like to acknowledge the Captain, officers and crew of the R/V SA Agulhas II for their immense efforts in navigating us to and aiding us in sampling one of the most remote regions of our planet, as well as Dr. John Shears for his leadership of the expedition. KH would like to extend her gratitude to Frazer Christie and Christene Batchelor for discussions during the expedition and to Keith Nicholls for providing the JR71 CTD data and engaging in discussions on the data differences. Further thanks go to Raquel Flynn for assistance with the oxygen concentration measurements and Sibylle Téchené for her help with coding of the OMP analysis. KH is funded by the South African National Antarctic Programme (SANAP), iAtlantic Horizon 2020 (grant agreement 818123) and the Centre National de la Recherche Scientifique (CNRS) through the European Union's Horizon 2020 research and innovation programme (grant agreement 821926; IMMERSE project). JBS has received funding from the European Union's Horizon 2020 research and innovation program (grant agreement 637770). SEF acknowledges support from SANAP (grants 105539 and 110735), the University of Cape Town Vice-Chancellor's Future Leaders 2030 Fund, and BIOGRIP (South African Department of Science and Innovation). The CTD data are available at DOI: 10.5281/zenodo.3357972 and the IBSCO bathymetric data are available at DOI: $10.1002 / \mathrm{grl} .50413$ 


\section{References}

Absy, J. M., M. Schröder, R. Muench, and H. Hellmer (2008). Early summer thermohaline characteristics and mixing in the western Weddell Sea. Deep Sea Research Part II: Topical Studies in Oceanography, 55(8), pp.1117-1131.

Abrahamsen, E.P., A.J. Meijers, K.L. Polzin, A.C.N. Garabato, B.A. King, Y.L. Firing, J.B. Sallée, K.L. Sheen, A.L. Gordon, B.A. Huber, and M.P. Meredith (2019). Stabilization of dense Antarctic water supply to the Atlantic Ocean overturning circulation. Nature Climate Change, 9(10), pp.742-746.

Adusumilli, S., H.A. Fricker, M.R. Siegfried, L. Padman, F.S. Paolo, and S.R. Ligtenberg (2018). Variable basal melt rates of Antarctic Peninsula ice shelves, 1994-2016. Geophysical Research Letters, 45(9), pp.4086-4095.

Arndt, J.E., H. W. Schenke, M. Jakobsson, F. Nitsche, G. Buys, B. Goleby, M. Rebesco, F. Bohoyo, J.K. Hong, J. Black, R. Greku, G. Udintsev, F. Barrios, W. Reynoso-Peralta, T. Morishita and R. Wigley (2013). The International Bathymetric Chart of the Southern Ocean (IBCSO) Version 1.0 - A new bathymetric compilation covering circum-Antarctic waters. Geophysical Research Letters, 40, pp. 3111-3117.

Bathmann, U., V. Smetacek, H,. De Baar, E. Fahrbach, and G. Krause (1994). The expeditions Antarktis X/6-8 of the research vessel Polarstern in 1992/93. Reports on Polar Research, 135, pp.236.

Fahrbach, E., G. Rohardt, N. Scheele, M. Schröder, V. Strass, and A. Wisotzki (1995). Formation and discharge of deep and bottom water in the northwestern Weddell Sea. Journal of Marine Research, 53, pp.515-538.

Fer, I., E. Darelius and K.B. Daae. (2016). Observations of energetic turbulence on the Weddell Sea continental slope. Geophysical Research Letters, 43(2), pp.760-766.

Gade, H. G. (1979). Melting of ice in sea water: A primitive model with application to the Antarctic ice shelf and icebergs. Journal of Physical Oceanography, 9(1), pp.189-198.

Gordon, A. L. (1998). Western Weddell sea thermohaline stratification. Ocean, Ice and Atmosphere: Interactions at the Antarctic Continental Margin, Antarct.Res.Ser, 75, pp.215240 .

Gordon, A. L., B. A. Huber, H.H. Hellmer, \& A. Ffield (1993). Deep and Bottom Water of the Weddell Sea's Western Rim. Science (New York, N.Y.), 262(5130), pp.95-97.

Hellmer, H.H., O. Huhn, D. Gomis, and R. Timmermann, (2011). On the freshening of the 
northwestern Weddell Sea continental shelf. Ocean Science, 7(3), pp.305-316.

Holland, P. R., A. Brisbourne, H. F.J. Corr, D. Mcgrath, K. Purdon, J. Paden, H. A. Fricker, F. S. Paolo and A. H. Fleming (2015). Oceanic and atmospheric forcing of Larsen C IceShelf thinning. The Cryosphere, 9, pp.1005-1024.

Jenkins, A. and A. Bombosch (1995). Modeling the effects of frazil ice crystals on the dynamics and thermodynamics of Ice Shelf Water plumes. Journal of Geophysical Research, 100, pp.6967-6981.

Jullion, L., A.C. Naveira Garabato, M.P. Meredith, P.R. Holland, P. Courtois, and B.A. King (2013). Decadal freshening of the Antarctic Bottom Water exported from the Weddell Sea. Journal of Climate, 26(20), pp.8111-8125.

Johnson, G.C. (2008). Quantifying Antarctic bottom water and North Atlantic deep water volumes. Journal of Geophysical Research: Oceans, 113(C5).

Kerr, R., T.S Dotto, M.M Mata, and H.H. Hellmer (2018). Three decades of deep water mass investigation in the Weddell Sea (1984-2014): temporal variability and changes. Deep Sea Research Part II: Topical Studies in Oceanography, 149, pp.70-83.

Klatt, O., E. Fahrbach, M. Hoppema, and G. Rohardt (2005). The transport of the Weddell Gyre across the Prime Meridian. Deep Sea Research Part II: Topical Studies in Oceanography, 52(3-4), pp. 513-528.

Nicholls, K.W., C. Pudsey, and P. Morris (2004). Summertime water masses off the northern Larsen C Ice Shelf, Antarctica. Geophysical Research Letters, 31(9), pp.1-4

Nicholls, K. W., S. Østerhus, K. Makinson, T. Gammelsrød, and E. Fahrbach (2009). Iceocean processes over the continental shelf of the southern Weddell Sea, Antarctica: A review. Reviews of Geophysics, 47(3), pp.1-23

Nicholls, K.W., K. Makinson, and E.J. Venables (2012). Ocean circulation beneath Larsen C Ice Shelf, Antarctica from in situ observations. Geophysical Research Letters, 39, pp.1-6.

Orsi, A., G. Johnson, and J. Bullister (1999). Circulation, mixing, and production of Antarctic Bottom Water. Progress in Oceanography, 43(1), pp.55-109.

Poole R. and M. Tomczak (1999) Optimum multiparameter analysis of the water mass structure in the Atlantic Ocean thermocline. Deep Sea Research Part I: Oceanographic Research Papers, 46, pp. 1895-921.

Purkey, S.G. and Johnson G.C. (2013). Antarctic Bottom Water warming and freshening: Contributions to sea level rise, ocean freshwater budgets, and global heat gain. Journal of 
Climate, 16, pp. 6105-22.

Robertson, R., M. Visbeck, A.L. Gordon, and E. Fahrbach (2002). Long-term temperature trends in the deep waters of the Weddell Sea. Deep Sea Research Part II: Topical Studies in Oceanography, 49(21), pp.4791-4806.

Shepherd, A., D. Wingham, T. Payne, and P. Skvarca (2003). Larsen ice shelf has progressively thinned. Science, 302, pp.856-859.

Shepherd, A., D. Wingham, and E. Rignot (2004). Warm ocean is eroding West Antarctic ice sheet. Geophysical Research Letters, 31, pp.1-4.

Thompson, A. F., A.L. Stewart, P. Spence, and K.J. Heywood (2018). The Antarctic slope current in a changing climate. Reviews of Geophysics, 56(4), pp.741-770.

Timmermann, R., A.L. Brocq, T. Deen, E. Domack, P. Dutrieux, B. Galton-Fenzi, H.

Hellmer, A. Humbert, D. Jansen, A. Jenkins, and A. Lambrecht (2010). A consistent data set of Antarctic ice sheet topography, cavity geometry, and global bathymetry. Earth System Science Data, 2(2), pp.261-273.

Tomczak, M. (1981). A multi-parameter extension of temperature/salinity diagram techniques for the analysis of non-isopycnal mixing. Progress in Oceanography, 10, pp. 147171.

van Caspel, M., M. Schröder, O. Huhn, and H. Hellmer (2015). Precursors of Antarctic Bottom Water formed on the continental shelf off Larsen Ice Shelf. Deep Sea Research Part I: Oceanographic Research Papers, 99, pp.1-9.

Williams, P.L. and N.W. Jenkinson (1982). A transportable microprocessor-controlled precise Winkler titration suitable for field station and shipboard use. Limnology and Oceanography, 27(3), pp.576-584. 


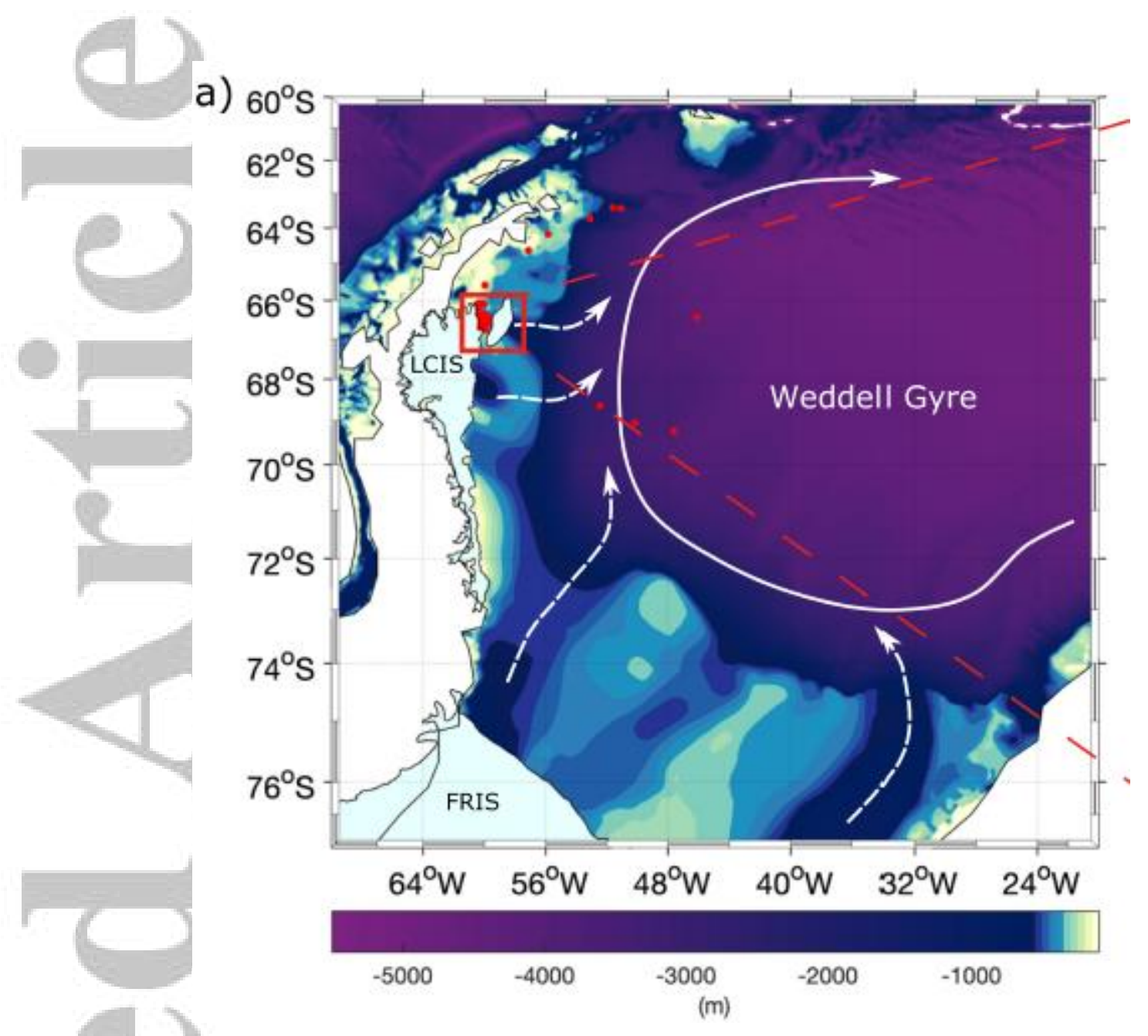

Figure 1. Topography of the Weddell Sea (m) (from IBSCO, Arndt et al., [2013]) shown by background shading for (a) the whole Weddell Gyre, (b) the area of interest adjacent to the northern sector of LCIS (position of iceberg A-68 shown for January 2019). The locations of CTD stations occupied during the Weddell Sea Expedition 2019 are shown as red dots with the subset of yellow dots in (b) indicating the stations where candidate source waters for Ice Shelf Water were detected. The red lines connecting the stations in (b) refer to the sections presented in Figure 2. Aspects of the general circulation for the Weddell Sea are illustrated in (a), with the Antarctic Slope Current (solid white arrow) and sinking parent waters of Antarctic Bottom Water (dashed white arrows) represented. 


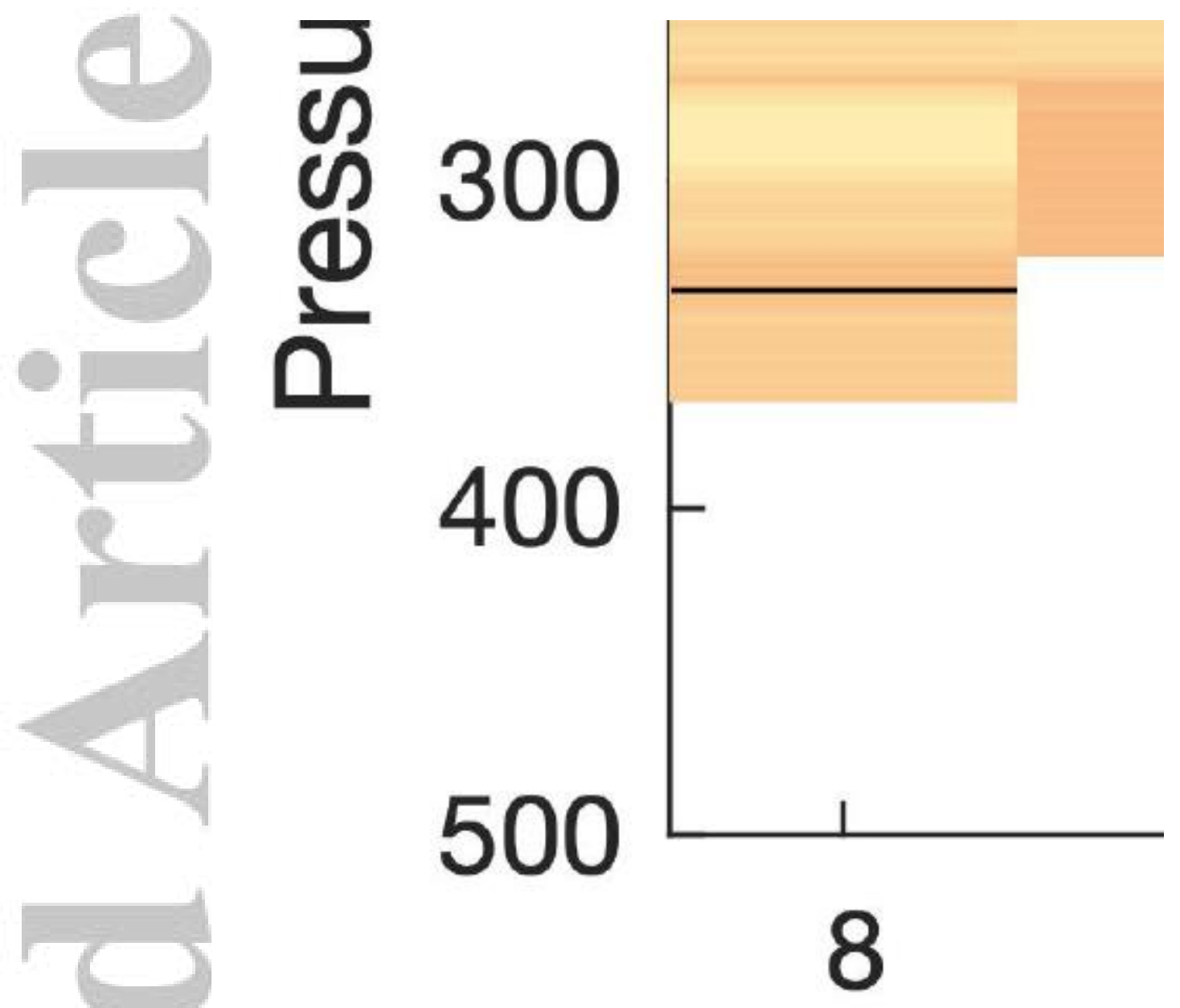

Figure 2. Vertical sections of oceanographic properties versus pressure measured a-c) along the ice shelf front and d-f) along the southern slope of Jason Trough up to the ice shelf. Potential temperature $(\mathrm{a}, \mathrm{d})$, salinity $(\mathrm{b}, \mathrm{e})$ and dissolved oxygen concentration $(\mathrm{c}, \mathrm{f})$ are shown as background shading with density contours $\left(\mathrm{kg} / \mathrm{m}^{3}\right)$ overlaid and labeled in $\mathrm{c}$ and $\mathrm{f}$. 

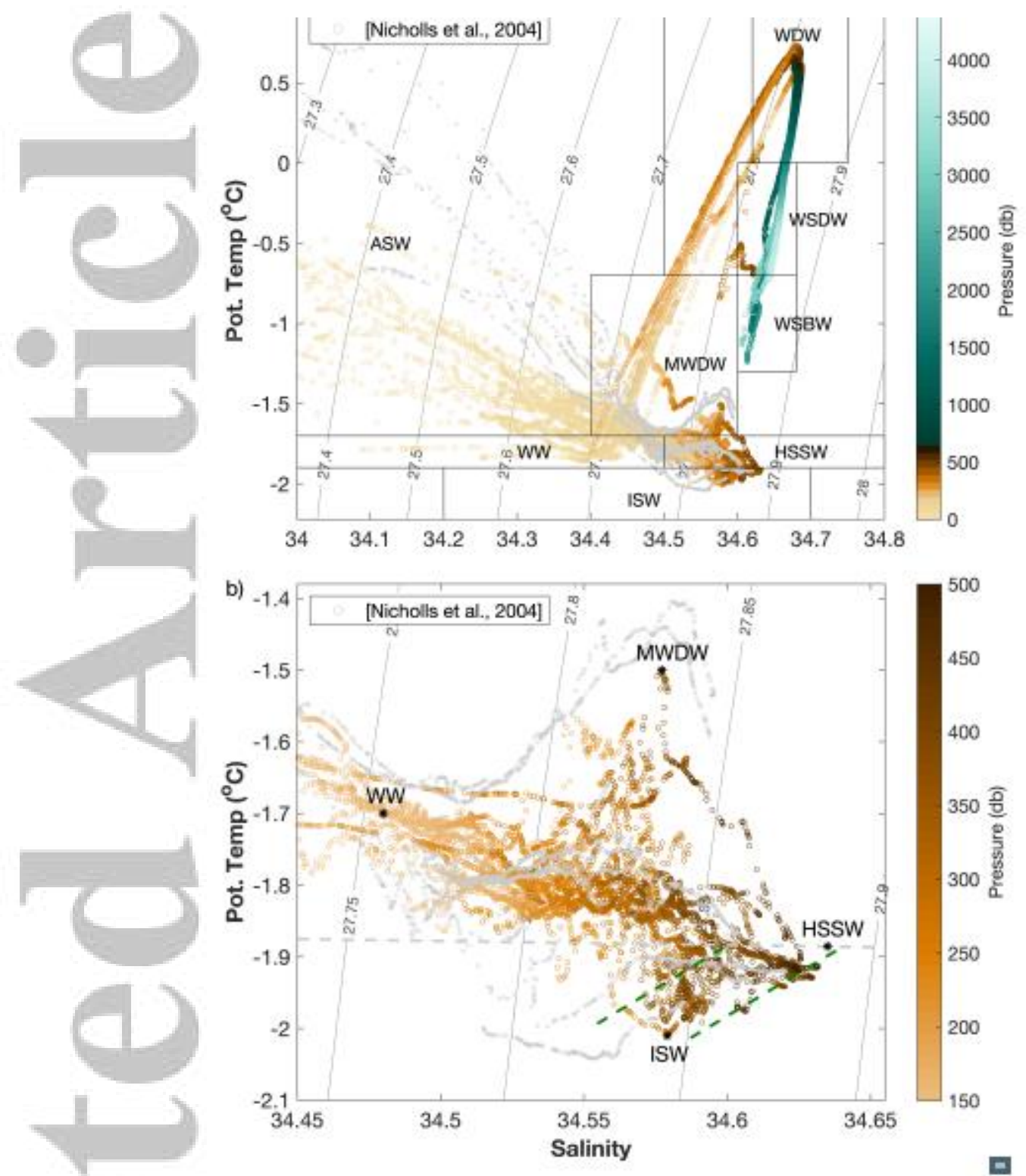

Figure 3. Oceanographic data plotted in temperature-salinity space from (a) all 29 CTD casts conducted in the Weddell Sea during WSE2019 and (b) a selection of the CTD data below 100 $\mathrm{m}$ from the area of the continental shelf where Jason Trough abuts LCIS. The colour shading indicates the pressure at which each measurement was made. The grey horizontal dotted line in (b) shows the surface freezing point of seawater, and the green lines represent Gade mixing lines of \pm 1 standard deviation from the mean of measured ISW properties (see text for details). The grey data points are from Nicholls et al. [2004]. Water mass labels indicate the thermohaline properties of Antarctic Surface Water (ASW), Winter Water (WW), Ice Shelf Water (ISW), High Salinity Shelf Water (HSSW), Warm Deep Water (WDW), Modified Warm Deep Water (MWDW), Weddell Sea Deep Water (WSDW), and Weddell Sea Bottom Water (WSBW). Note that the black points in (b) represent the end-member values of the source water types used for the mass balance analysis (see Section 4). 

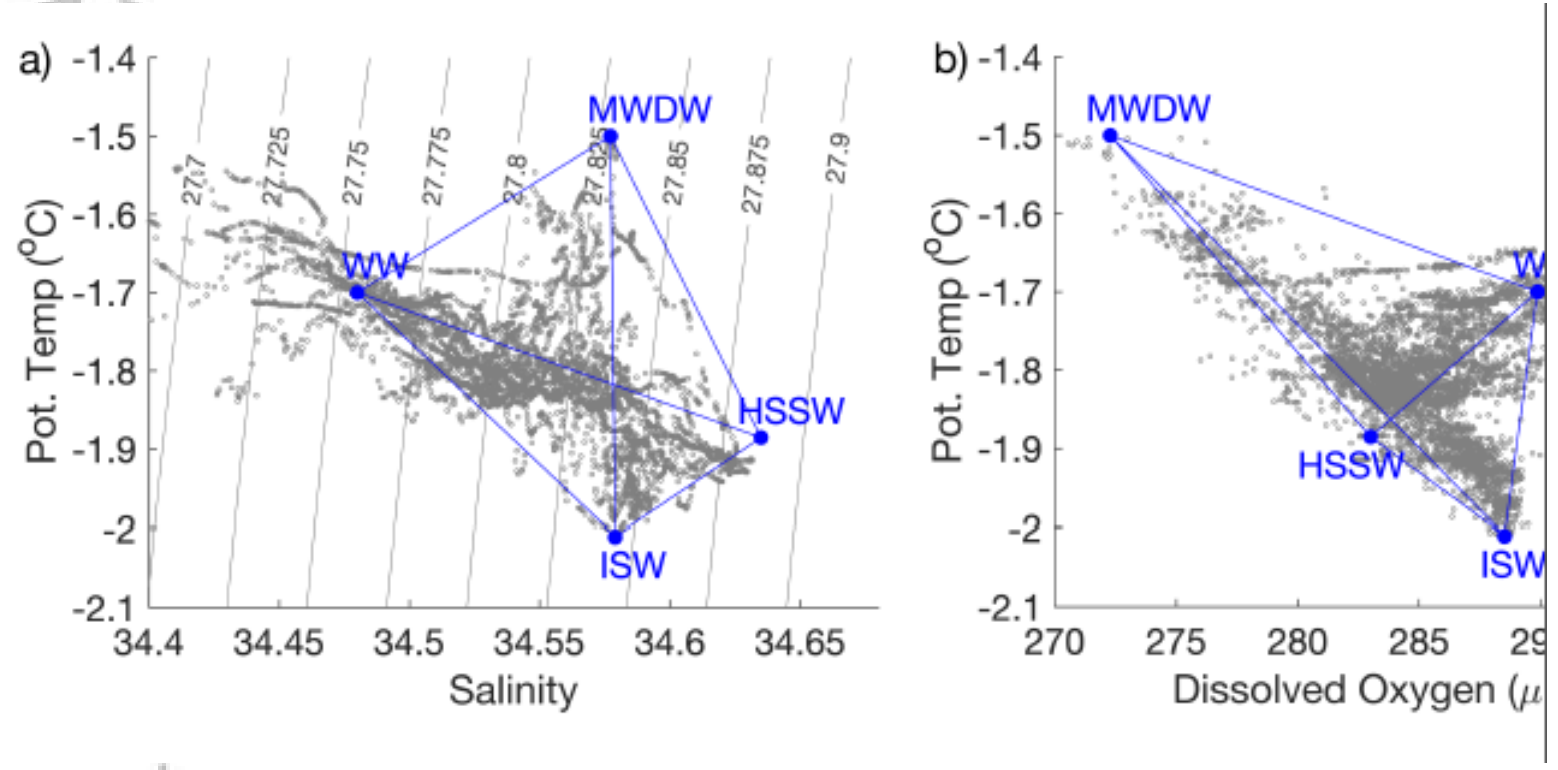

Figure 4. Oceanographic data below 150 dbar overlaid with source water type values plotted in a) temperature versus salinity, b) temperature versus oxygen and c) salinity versus oxygen space. The blue lines illustrate the linear mixing assumed for the OMP analysis. All data outside of the blue lines are outside the mixing matrix and are thus excluded from Figure 5.

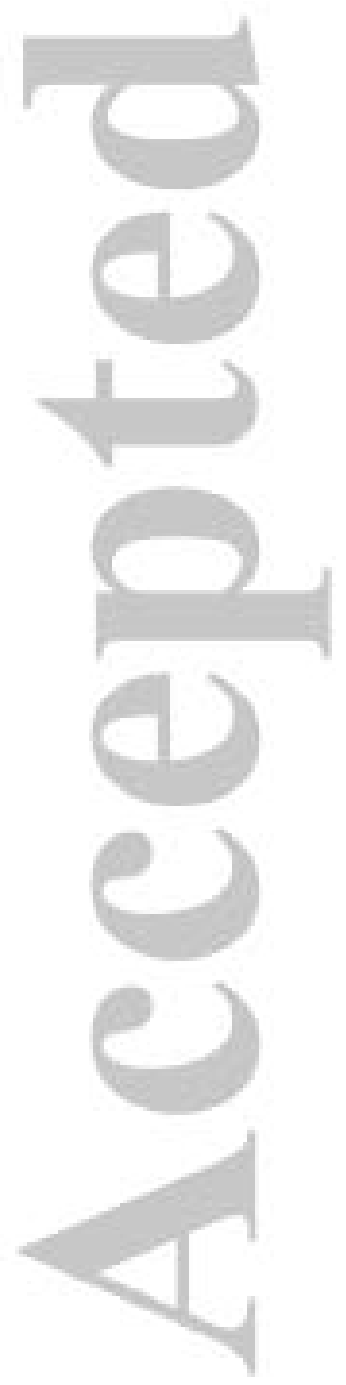



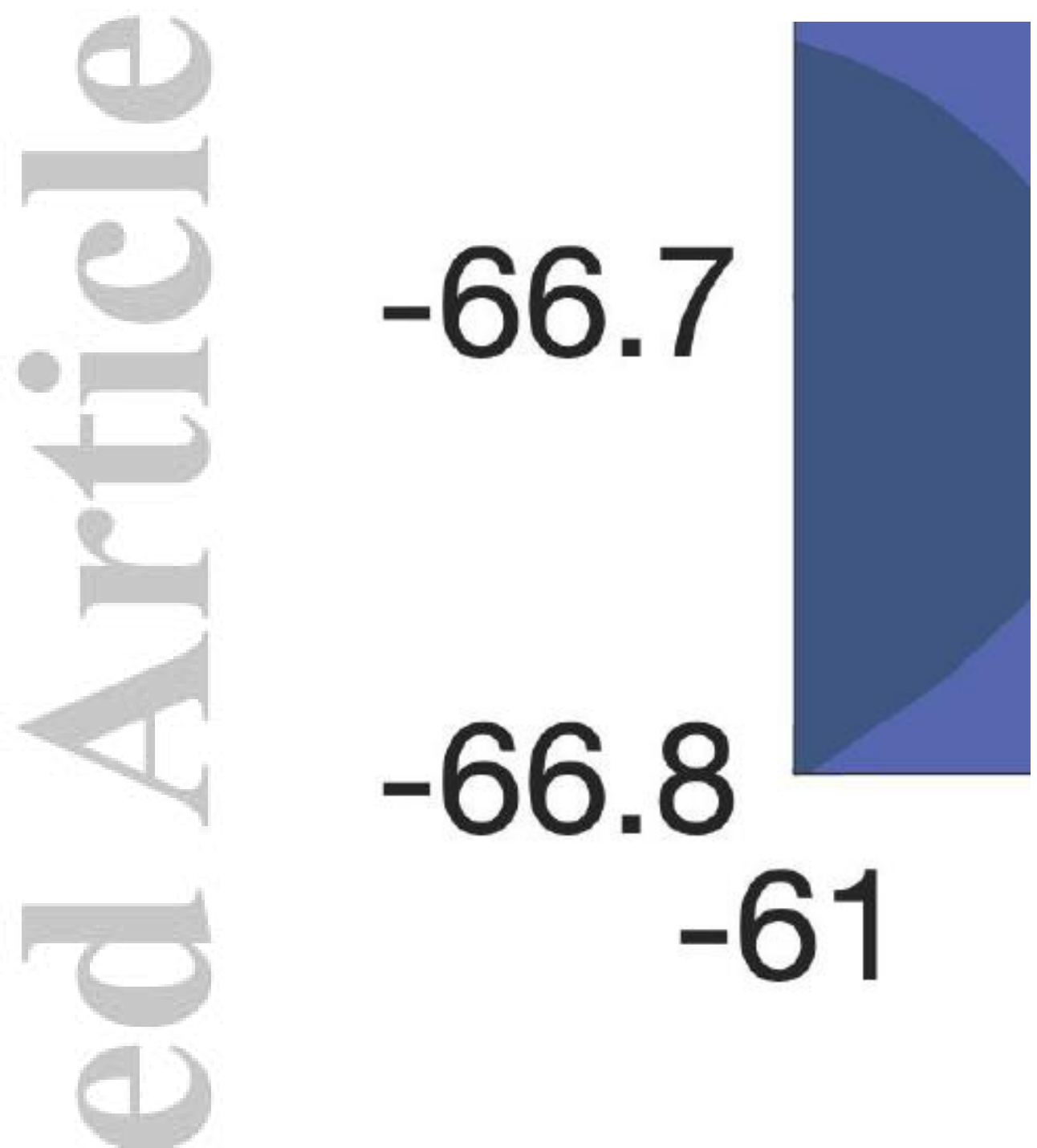

Figure 5. Maps showing the fractional contribution of each water mass to the oceanographic properties measured in the density layers (a) $27.75-27.775 \mathrm{~kg} / \mathrm{m}^{3}$, (b) $27.775-27.80 \mathrm{~kg} / \mathrm{m}^{3}$, (c) $27.80-27.825 \mathrm{~kg} / \mathrm{m}^{3}$, (d) $27.825-27.85 \mathrm{~kg} / \mathrm{m}^{3}$ and (e) $27.85-27.875 \mathrm{~kg} / \mathrm{m}^{3}$ with bathymetry (from IBSCO, Arndt et al., [2013]) as background shading. In cases where the stations are too shallow to have data for a particular density layer, or the data lies outside of the linear mixing matrix, no marker is used. The circles of subplot (f) indicate the heat content anomalies from the region averaged mean for the 150-350 dbar depth interval, with white and black denoting positive and negative anomalies, respectively. The labels 1-19 are the station numbers and light grey shading shows LCIS to the west and iceberg A-68 to the east. 